\title{
Dispersión urbana en el Suelo No Urbanizable del País Vasco: la distorsión del planeamiento en la Reserva de la Biosfera de Urdaibai ${ }^{1}$
}

\section{Urban sprawl in non-urban area in the Basque Country: the distortion of planning in the Urdaibai Biosphere Reserve}

\author{
Ma José Ainz Ibarrondo*, Aitor Bilbao Uribarri**, \\ Roberto Torres Elizburu***
}

\section{INTRODUCCIÓN}

El informe «Cambios de ocupación del suelo en España» (Observatorio de la Sostenibilidad en España, 2006) si bien reconoce cierta moderación de la tasa de artificialización del suelo en el País Vasco —durante el período 1987 2000 se registra un incremento del 13,9\%, frente al 29,5\% del conjunto estatal—, alerta respecto al hecho de que la mayor parte del suelo artificializado se corresponde con formas urbanas de carácter laxo y urbanizaciones exentas o ajardinas que en el período analizado han aumentado su superficie en un $30 \%$. Efectivamente, durante las tres últimas décadas se produce un cambio de tendencia en el proceso de urbanización; frente a la concentración con cierto grado incluso de hacinamiento de décadas anteriores, se asiste a una

${ }^{1}$ Este trabajo se ha realizado dentro del Proyecto de Investigación UNESCO06/12: "Impactos ambientales de la urbanización difusa en la RBU", financiado por la Cátedra Unesco de la UPV/EHU. IP Ma José Ainz Ibarrondo.

* Profesora Titular. Departamento de Geografía, UPV/EHU (mj.ainz@ehu.es).

** Funcionario interino. Gobierno Vasco (aitorbiur@gmail.com).

*** Profesor laboral interino. Departamento de Geografía, UPV/EHU (roberto.torres@ehu.es). 
dispersión del fenómeno urbanizador asociado a densidades en general más bajas, y en medida creciente a fórmulas de vivienda unifamiliar.

En definitiva, indicios propios del denominado urban sprawl que, no obstante, presenta en el País Vasco un vector especialmente pernicioso en cuanto que en parte se desarrolla sobre Suelo No Urbanizable a partir de la figura urbanística del Núcleo Rural, consolidada en la Ley vasca 2/2006 de Suelo y Urbanismo. Bilbao Uribarri (2007) alertaba respecto a la posibilidad de que la aplicación de dicha figura podía contribuir a generalizar el modelo de la ciudad difusa al conjunto del territorio, dando lugar, en los municipios de menor entidad poblacional, a un desarrollo polinuclear carente de funcionalidad. El análisis que a continuación se realiza pretende medir la materialización y dimensión real del proceso en los municipios que integran la Reserva de la Biosfera de Urdaibai, una vez que ha transcurrido una década desde la incorporación de la mencionada figura al planeamiento municipal.

\section{LA URBANIZACIÓN DIFUSA EN LA CAPV}

Durante las últimas décadas y especialmente a partir del Censo de 1991, se ha venido observando en el País Vasco un cambio de sentido en los movimientos internos de la población. Si durante la etapa industrial predominó un proceso de concentración urbana paralelo a un progresivo vaciamiento de las comarcas rurales, mediada la década de 1980 las densas áreas urbano-industriales ralentizan sus tasas de crecimiento poblacional, llegando muchas de ellas incluso a conocer pérdidas de población. Al mismo tiempo, zonas de carácter rural bien conectadas con los espacios urbanos tradicionales empiezan a ganar población como consecuencia de la relocalización residencial de familias urbanas.

Durante el periodo 1991-2006 las migraciones internas en el País Vasco alcanzan sus mayores tasas en las comarcas situadas en la margen derecha del «Gran Bilbao», en los pueblos que rodean la capital alavesa y siguen hacia el SO por la carretera N-I y, aunque con una menor intensidad, también en los municipios localizados en los márgenes de esta misma infraestructura a su paso por las comarcas guipuzcoanas de Donostialdea y Tolosaldea. Además, las tasas de crecimiento demográfico positivas se concentran en municipios con una población inferior a los 10.000 habitantes, siendo aquellos con menos de 2.500 habitantes los que presentan mejores resultados. En este caso, el factor responsable del incremento poblacional ha sido el saldo migratorio positivo, en tanto que el natural sigue siendo negativo en gran parte de estas pequeñas localidades, dado el envejecimiento heredado del éxodo rural. 
FIGURA 1

LA URBANIZACIÓN DIFUSA EN LA CAPV

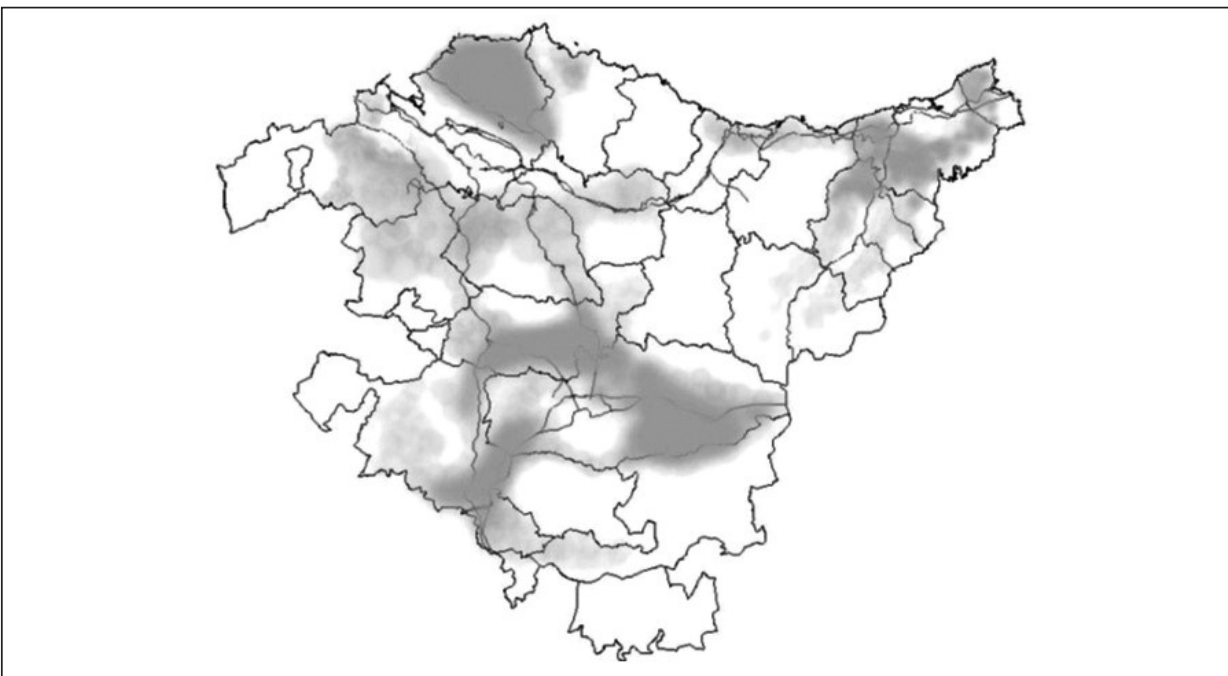

Fuente: Eustat. Elaboración propia.

Buena parte de las áreas urbanas del País Vasco se localizan sobre valles con escasas superficies llanas y fuertes pendientes en las laderas, añadiéndose a las elevadas densidades la ausencia de planificación, y al desorden urbano, la contaminación ambiental. La carestía del suelo, pero también la aspiración de una parte de la sociedad a una mayor calidad del espacio residencial, unidos al extraordinario dinamismo del sector inmobiliario y la construcción en los años de coyuntura económica expansiva, están en la base de los movimientos demográficos aludidos más arriba. Lógicamente, las áreas de destino han registrado un incremento importante del parque de vivienda, preocupante en cuanto que se materializa a partir de un elevado consumo de suelo, derivado de las morfologías de baja densidad por las que se opta y que se justifican en el intento de integrar las nuevas urbanizaciones en espacios de carácter rural.

Este proceso, claramente asimilable al denominado urban sprawl, se materializa en el territorio como una orla en torno a los primitivos pueblos, pero también de forma mucho más difusa, rellenando intersticios entre el caserío disperso que constituye el hábitat rural propio de la vertiente vasco-atlántica. Es precisamente en este segundo vector de la urbanización difusa, nunca mejor calificada, en el que va a centrarse este análisis, dado el mayor riesgo que 
entraña en cuanto que multiplica los costes energéticos, de infraestructuras... la banalización del paisaje y la pérdida de recursos al afectar no ya a sectores más o menos amplios del territorio, sino a todo él en su conjunto, incluidas áreas de especial valor como la propia Reserva de la Biosfera de Urdaibai. Pero en el caso del País Vasco, al factor de riesgo respecto al urban sprawl que constituye la existencia previa de un hábitat disperso, se añade la cobertura legal del proceso en el Suelo No Urbanizable (SNU) a partir del desarrollo de la figura urbanística del Núcleo Rural (NR).

\section{Los NúCleos RuRales del País Vasco}

En el poblamiento disperso propio del ámbito rural vasco-atlántico el caserío absolutamente solo o aislado alterna con pequeñas agrupaciones normalmente de 4 a 8 caseríos, aunque los límites puedan situarse entre 2 y 15 unidades, estructurados en torno a un mínimo espacio común y sin que llegue a constituirse un plano urbano. La Ley vasca 5/98 de Medidas Urgentes en Materia de Régimen de Suelo y Ordenación Urbana primero, y la Ley 2/2006 de Suelo y Urbanismo del País Vasco después elevan esa realidad del poblamiento rural vasco a figura urbanística bajo la denominación Núcleo Rural que se constituye, junto al Suelo Común y Protegido, en una de las tres categorías en que puede clasificarse el Suelo No Urbanizable.

\section{Los Núcleos Rurales en el hábitat disperso del País Vasco}

El hábitat rural del País Vasco está dado en su vertiente atlántica por el caserío, entendido como unidad de explotación agraria en la que casa y tierras se constituyen en un coto redondo. La primera referencia al término caserío data del siglo XIII y a partir de entonces se hace progresivamente frecuentes en los textos bajomedievales, en referencia a un tipo de poblamiento con un grado de dispersión superior al que hasta entonces dominaba (García de Cortazar et al., 1985). Esa tendencia a la colonización dispersa del territorio había cuajado plenamente en el siglo XviII; para entonces el caserío estaba instalado en todos aquellos sectores en los que la pendiente presentaba valores inferiores al 30\% y la altura no sobrepasaba los $500 \mathrm{~m}$, límite de los cultivos habituales en la zona. A estos sectores se añadía una banda limítrofe donde las pendientes alcanzaban e incluso llegaban a superar el $40 \%$, consecuencia de la necesidad de incrementar los recursos productivos desde las heredades primi- 
tivas, que por sus mejores condiciones topográficas aconsejaron la fundación de caseríos (Ainz Ibarrondo, 2001).

La colonización dispersa a partir del caserío propició además de un nivel de ocupación del territorio superior al del resto del cantábrico, la organización individual del terrazgo a partir de esas «diminutas células» que forman «un complejo mosaico de infinitas teselas», según la expresión de García Fernández (1975), particularizando el espacio rural vasco dentro del dominio atlántico. No obstante, todo ello no implica que el caserío necesariamente aparezca solo, aislado. Con frecuencia, mayor en Bizkaia que en Gipuzkoa, los caseríos se agrupan en pequeñas barriadas de 4 a 8 unidades. Si en el caserío absolutamente aislado la vivienda tiende a situarse en mitad de sus tierras, en las agrupaciones es el núcleo de viviendas el que suele estar emplazado en el centro del conjunto que forman las parcelas de todos los caseríos.

El hábitat disperso comienza a perder funcionalidad en las primeras décadas del siglo $\mathrm{xx}$, a medida que el caserío deja de ser viable como explotación agraria. Tras el parón propiciado por la guerra civil, el abandono de caseríos afectó a barrios enteros, particularmente a los peor comunicados con los centros industriales; en los valles más excéntricos del territorio el abandono pudo alcanzar hasta un tercio del total. No obstante, la mejora de los medios de transporte y especialmente la generalización del coche permitió la consolidación de la agricultura a tiempo parcial en Bizkaia y Gipuzkoa, de manera que mediada la década de 1970 había cesado el proceso de abandono de caseríos, dando paso en la década siguiente al fenómeno contrario (Ainz Ibarrondo, 1999).

«Por un cúmulo de matices de compleja y curiosa raíz psicológica y social, el hecho es que "los caseríos están de moda"» (Etxezarreta Zubizarreta, 1977, p. 361). Efectivamente, localizado en un entorno privilegiado y próximo respecto a los congestionados fondos de valle de la vertiente vasco-atlántica, el caserío sigue de moda, aunque únicamente en cuanto que vivienda y no ya como explotación agraria. No obstante, desde la óptica del hábitat pudiera parecer que se ha abierto una nueva época de expansión del caserío ya que si bien es cierto que algunos de los caseríos abandonados han sido recuperados y prácticamente todos rehabilitados, a partir de los años 1980 en las inmediaciones de los antiguos caseríos comienza a proliferar con fuerza creciente la vivienda unifamiliar de nueva planta, con una marcada querencia hacia la tipología arquitectónica del caserío, que se recrea con peor o mejor acierto. Pero el caserío está aportando además del modelo arquitectónico, el modelo de poblamiento, ya que la urbanización difusa se materializa sobre esa multitud de «pequeñas células» en que el caserío organizó el espacio rural. 
La construcción de vivienda unifamiliar en suelo rústico, sobre las praderas que circundan el caserío, durante los años 1980 y 1990 se amparó en la excepción prevista en el Texto Refundido de la Ley del Suelo de 1976, que a pesar de prohibir genéricamente la transformación urbanística del SNU, abría la puerta a nuevas edificaciones e instalaciones (art. 85 y 86). Así excepcionalmente, a través de un procedimiento específico de autorización por la Comisión Provincial de Urbanismo, cabía la posibilidad de edificar vivienda aislada en SNU, siempre «que no exista la posibilidad de formación de un núcleo de población». En el caso de Bizkaia, el órgano urbanístico foral competente interpretó que con parcelas de $10.000 \mathrm{~m}^{2}$ quedaba descartado el riesgo de formación de núcleo urbano; una interpretación que si bien nunca alcanzó rango normativo, se aplicó tan masivamente que dejó de considerarse una excepción para entenderse como derecho adquirido por los propietarios de suelo rústico.

A lo largo de los años 1980 y primeros 1990 la proliferación de vivienda unifamiliar en SNU había adquirido tal envergadura que las Directrices de Ordenación del Territorio del País Vasco (DOTPV, 1997) en su Decreto de aprobación señalan²: «En el suelo no urbanizable se prohíbe el uso de la vivienda unifamiliar o bifamiliar aislada salvo en aquellos casos en que, fehacientemente, se demuestre su vinculación a la explotación de los recursos agropecuarios» (art. 10.1). Esta prohibición no fue acompañada de ninguna norma general que definiera lo que debía considerarse la vinculación suficiente a una explotación agraria, de manera que de nuevo se recurrió al criterio interpretativo hasta que la Ley 2/2006 del Suelo del País Vasco ha introducido un índice normativo objetivo, según el cual es preciso que en la última declaración de la renta presentada más del $50 \%$ de los ingresos corrientes del solicitante provengan de la explotación agropecuaria (art. 31.1.c).

Probablemente tampoco ahora se habrá acabado con la compra o constitución de explotaciones agrarias únicamente con el fin de obtener la codiciada licencia de edificación aislada en SNU, si bien el endurecimiento de la normativa podría estar dando lugar a un proceso de gentrificación en áreas de mayor valor paisajístico. Pero a día de hoy el urban sprawl en SNU se materializa sobre todo a partir de la opción contemplada por el propio Decreto de aprobación de las DOTPV, donde se señala que «la demanda de vivienda unifamiliar o bifamiliar aislada en medio rural ha de ir dirigida hacia los núcleos rurales o ámbitos clasificados y calificados urbanísticamente para acoger tal uso» (art. 10.2). Los Núcleos Rurales a los que se alude no son sino esos cientos de pe-

\footnotetext{
2 Decreto 28/1997, de 11 de febrero, de aprobación definitiva de las Directrices de Ordenación del Territorio del País Vasco.
} 
queños barrios de caseríos que junto al caserío absolutamente disperso integran el hábitat rural vasco-atlántico. En Bizkaia, territorio que presenta una mayor dominancia del Núcleo Rural como forma de hábitat y también una mayor tendencia hacia el desarrollo urbanístico de éstos, de 1999 a 2009 el uso residencial en SNU ha pasado de ocupar 1.783 ha a 2.572 ha; un incremento de prácticamente el $45 \%$, muy por encima del desarrollo de los suelos urbanos y urbanizables que en conjunto se incrementan en poco más del 6\%; en otras palabras, el $60 \%$ del incremento de suelo residencial se concentra en los últimos 10 años en SNU (UDALPLAN).

\section{El Núcleo Rural como figura urbanística}

En la Legislación del Suelo vasca, el Núcleo Rural debe diferenciarse de los núcleos enclavados en los suelos urbanos de los municipios considerados rurales, que tienen un régimen jurídico idéntico a los demás núcleos urbanos. Esta calificación de Núcleo Rural está dedicada a las pequeñas agrupaciones de caseríos aludidas más arriba, que se ubican en SNU. Su especialidad reside en que aún formando parte de esta clasificación de suelo, la ley permite en ellos nuevos crecimientos residenciales no vinculados a explotación agropecuaria. Este régimen especial contradice paradójicamente los objetivos estratégicos que la legislación del suelo y la ordenación territorial atribuyen al $\mathrm{SNU}^{3}$.

La primera regulación urbanística de los Núcleos de Población Rural se encuentra en la Ley 5/98 de Medidas Urgentes en Materia de Régimen de Suelo y Ordenación Urbana, aprobada en el País Vasco tras la Sentencia del Tribunal Constitucional 61/1997, según la cual la competencia en materia de ordenación territorial y urbanística corresponde en exclusiva a las Comunidades Autónomas. En su principio general, la Ley 5/98 se manifestaba en línea con la doctrina establecida en las DOTPV respecto al intenso proceso de construcción de vivienda unifamiliar en SNU: «[...] especial atención deberá otorgarse a los usos residenciales en edificaciones dispersas, cuyos efectos sobre la ocupación del suelo y su impacto sobre el medio va mucho más allá del espacio físico que efectivamente ocupan» (Gobierno Vasco, Directriz 8, 1997). Sin

\footnotetext{
${ }^{3}$ Este apartado sintetiza el análisis realizado en el artículo "Los núcleos rurales en el País Vasco como precursores de la dispersión urbana: la reserva de la biosfera de Urdaibai" (Bilbao Uribarri, 2007), con las actualizaciones precisas tras la entrada en vigor del Decreto 105/2008 de desarrollo de la Ley 2/2006.
} 
embargo, al principio general se «[...] le calza una auténtica excepción, los denominados Núcleos Rurales» (Bilbao Uribarri, 2007, p. 85).

En el SNU la ley 5/98 formuló tres tipos de calificaciones: «Protegido, Común y Núcleo Rural». El NR se definió como aquellas «agrupaciones de seis o más caseríos en torno a un espacio público que los aglutina y confiere su carácter» (art. 1.1.b), posibilitándose un desarrollo edificatorio residencial no vinculado a la actividad agropecuaria, que puede ampliar el número de nuevas viviendas del NR hasta doblar el número de las preexistentes, sin que el total llegue a superar las 30 unidades.

La inclusión de la categoría NR resulta una novedad significativa puesto que hasta entonces la legislación del suelo estatal de referencia (LS/76, LS/92 y LS/98) había proclamado que en SNU debía evitarse, precisamente, la formación de núcleos de población desconectados de los núcleos urbanos existentes. La Ley vasca, a pesar de la novedad que introducía, no ofreció ningún argumento urbanístico sustantivo para su justificación, señalándose incidentalmente en la exposición de motivos que los NR «ya venían siendo recogidos por el planeamiento municipal como ámbitos diferenciados, pero sin que hubiera hasta este momento una regulación legal sobre los mismos». Esto es, se trataría únicamente de legalizar una práctica del planeamiento municipal, que hasta entonces era plenamente irregular. Sorprende esta apuesta del legislador vasco, más aún tratándose de una ley de coyuntura, provocada por la sentencia del Tribunal Constitucional, y transitoria, hasta que se aprobara una ley urbanística integral.

La aplicación de Ley de Medidas Urgentes 5/98 propició un desarrollo de los NR sobre el que alertan algunos documentos de planificación, como los Planes Territoriales Parciales de las Áreas Funcionales de Gernika-Markina y Durango: «su desarrollo residencial comienza a desfigurar el modelo tradicional, y los núcleos rurales corren el peligro de convertirse en urbanizaciones turísticas, con una merma de la calidad de vida en el núcleo original y un impacto territorial de consecuencias medioambientales, económicas y sociales» (Diputación Foral de Bizkaia, 2002, p. 300). No obstante, la Ley 2/2006 de Suelo y Urbanismo del País Vasco (LSUPV) vuelve a recoger con pocos cambios la categoría NR en SNU, sin que las consecuencias de su aplicación efectiva durante los años siguientes a la aprobación de la Ley 5/98 llamara a ningún tipo de reflexión durante el proceso de elaboración y aprobación de la LSUPV.

En esta nueva Ley se comparten los principios de valoración y necesaria protección del suelo rústico expresados en las DOTPV del año 1997 —principio de ocupación sostenible del suelo, evitando la segregación y dispersión ur- 
bana (art. 3)—, concretándose en los criterios de clasificación del SNU (art. 13) y el régimen de usos y actividades permitidos (art. 28), donde se reitera la prohibición de nuevas edificaciones destinadas a vivienda. Además, en su Exposición de Motivos, la LSUPV manifiesta una severa crítica a «la tendencia a la extensión de la práctica urbanística de crecimiento urbano en desarrollos esponjados y en baja densidad, en una comunidad autónoma que carece de suelo apto para urbanizar en grandes partes de su territorio», llegando el legislador «a la conclusión de que dicho modelo debe ser revisado en profundidad y con carácter urgente» (apdo. II.2).

Este principio de urbanismo sostenible se materializa en el capítulo dedicado a estándares y cuantías obligatorias para el planeamiento urbanístico municipal, donde se establecen unos estándares de edificabilidad mínima para los nuevos suelos a desarrollar, urbanos no consolidados y urbanizables, de $0,4 \mathrm{~m}^{2}$ techo/ $\mathrm{m}^{2}$ suelo en los municipios mayores de 3.000 habitantes, o con un núcleo urbano superior a 2.000 habitantes; y de $0,25 \mathrm{~m}^{2}$ techo/ $\mathrm{m}^{2}$ suelo para los municipios menores (art. 77, apdo. 4).

A pesar de tratarse de densidades relativamente bajas, en los NR ni siquiera se cumple con este estándar de densidad mínima que la Ley considera ambientalmente sostenible. Las Normas Subsidiarias municipales en vigor delimitan la parcela mínima edificable en NR en torno a una media de $2.500 \mathrm{~m}^{2}$. Así, con una edificabilidad de $400-450 \mathrm{~m}^{2}$ construidos por vivienda en las nuevas construcciones de mayor tamaño, aún se obtiene una densidad máxima de entre 4-8 viviendas/ha, según se trate de vivienda unifamiliar o bifamiliar, y una edificabilidad de $0,16-0,18 \mathrm{~m}^{2}$ techo/ $\mathrm{m}^{2}$ suelo. No obstante, puede suceder incluso que el planificador llegue a «lotizar» parcelas más grandes que la mínima establecida, circunstancia frecuente ya que suele tomarse como referente cartográfico la base catastral rústica, de forma que la parcela receptora de nueva edificación puede rondar los 5.000-10.000 $\mathrm{m}^{2}$. Todo ello en clara contradicción con los principios y exigencias de sostenibilidad de la propia Ley que los legaliza.

Así pues, por la vía de la excepción a la norma general, el art. 29 de la LSUPV establece un régimen específico para los NR que quedan definidos como: «la agrupación de entre seis y veinticinco caseríos en torno a un espacio público que los aglutina y confiere carácter». Respecto a la Ley 5/98, el límite del NR desciende de 30 a 25 viviendas, máximo a partir del cual la Ley deja abierta a la ambigüedad la posibilidad de que se clasifiquen también como suelo urbano «cuando así proceda conforme a esta ley» (art. 29.2). Por tanto, parece que el legislador cede absolutamente a la discrecionalidad de la competencia urbanística municipal la determinación de si un NR puede pasar 
a Suelo Urbano o mantenerse como Suelo No Urbanizable, según valore la concurrencia de los dos requisitos establecidos en su artículo 11: integración en la trama urbana existente y contar con los servicios urbanos consolidados, ambos conceptos jurídicos indeterminados.

Esta indefinición no está exenta de consecuencias, puesto que existen diferencias sustanciales en el régimen jurídico-económico de ambas clases de suelo que dan como resultado un régimen privilegiado para los desarrollos en NR, como se puede comprobar en el cuadro 1:

CUADRO 1

OBLIGACIONES LEGALES EN EL DESARROLLO REGLADO

DEL SUELO Y EL NÚCLEO RURAL

\begin{tabular}{|c|c|c|c|}
\hline & $\begin{array}{c}\text { Reparto } \\
\text { aprovechamiento }\end{array}$ & $\begin{array}{c}\text { Cesiones } \\
\text { obligatorias }\end{array}$ & $\begin{array}{c}\text { Estándares: } \\
\text { Vivienda Protección } \\
\text { Pública }\end{array}$ \\
\hline $\begin{array}{l}\text { Suelo Urbano no } \\
\text { consolidado y Suelo } \\
\text { Urbanizable }\end{array}$ & $\begin{array}{c}\text { 85\% privado/ } \\
15 \% \text { público } \\
\text { (Ley vasca } 11 / 08 \text { ) }\end{array}$ & $\begin{array}{c}\text { Viales, espacios } \\
\text { libres + sistemas } \\
\text { generales + } \\
\text { urbanización } \\
\text { Art.25 LSUPV 2/06 }\end{array}$ & $\begin{array}{c}40 \text { \% VPP Suelo } \\
\text { Urbano y } 75 \% \text { VPP } \\
\text { Suelo } \\
\text { Urbanizable(art. } 80 \\
\text { LSUPV 2/06) }\end{array}$ \\
\hline SNU Núcleo Rural & $\begin{array}{c}100 \% \text { privado } \\
\text { (art. } 27 \text { y } 29 \text { LSUPV } \\
2 / 06)\end{array}$ & $\begin{array}{l}\text { No existe } \\
\text { obligación }\end{array}$ & Ninguno \\
\hline
\end{tabular}

Fuente: Elaboración propia.

La diferencia del aprovechamiento urbanístico patrimonializable por el propietario de suelo es nada menos que del $15 \%$, en virtud de la Ley vasca 11/2008 por la que se modifica la participación de la comunidad en las plusvalías generadas por la acción urbanística. Se había hecho extensivo el trato de favor concedido tradicionalmente por la legislación urbanística a la vivienda vinculada a explotación agraria, justificado en la propia función del SNU como suelo destinado a fines agrícolas, forestales o ganaderos.

Con la autorización al agricultor para que construya su vivienda junto a las tierras que trabaja se brinda al profesional agrario la posibilidad de realizar su labor en las mejores condiciones posibles, sin que en principio exista por ello aumento del valor especulativo de ese suelo. Sin embargo, la Ley 5/98 permitió el 
crecimiento urbanístico de los NR con edificaciones a las que no se exige una relación funcional con el suelo rústico en el que se encuentran, de forma que el propietario puede vender sus parcelas en el mercado inmobiliario obteniendo sustanciales beneficios por su ubicación privilegiada en un entorno progresivamente valorado, sin que la comunidad participe de esas plusvalías al no imponérsele el sistema de cargas a que se sujeta el propietario en el suelo urbano y urbanizable. Todo ello lleva a Barrenetxea a afirmar: «Esta situación considero que es claramente inconstitucional» (Barrenetxea Apraiz, 2000, p. 57).

A este privilegio que se otorga a los promotores en NR por vía legal directa se suma otra diferencia importante, que es la referida a la exención de las cargas de ejecución de la urbanización y su cesión gratuita al Ayuntamiento (art. 25 LSUPV). En este punto, resulta del todo irreal la prohibición del art. 29.6 LSUPV, según la cual en los NR no podrán definirse nuevas dotaciones, ni vías públicas de nuevo trazado, cuando lo cierto es que se está realizando un enorme esfuerzo económico desde las haciendas públicas para dotar a estos barrios de caseríos de unos estándares de urbanización equivalentes a los del suelo urbano.

Este régimen jurídico privilegiado y carente de una justificación social aparente, puesto que los NR no están proyectados para fijar una población que se dedica a la actividad agraria — no se exige vinculación económica a dicha actividad, frente a lo que sucede en el resto del SNU—, está llevando a una situación paradójica. Se ha asumido tradicionalmente que el fomento de desarrollos urbanísticos por los Ayuntamientos, aquejados de falta de medios económicos, tenía también una intención recaudatoria; no obstante, en el caso de los NR se comprueba que las entidades locales dejan de recibir sustanciosas participaciones. Resulta a primera vista extraño que los Ayuntamientos se estén dedicando a promover desarrollos urbanísticos desde los NR con el afán que podemos comprobar en algunos municipios de la Reserva de la Biosfera de Urdaibai. En este sentido, llaman la atención los crecimientos residenciales en suelo no urbanizable, apoyados sobre estos NR, en relación al total previsto por el planeamiento en municipios como en Muxika (45,7\%), Murueta $(42,4 \%)$, Kortezubi $(37,6 \%)$ o Ereño $(33,7 \%)$.

Las DOTPV incluyen un modelo de cálculo que actúa a modo de límite reglamentario y vinculante del número máximo de viviendas a ofertar por el planeamiento urbanístico. Esta regla de cálculo no incorporó a la oferta máxima las viviendas que se planificaban en NR, en consecuencia, en los municipios donde se están multiplicando los NR existe una sobreoferta de viviendas que, además, inciden directamente sobre los pequeños núcleos urbanos donde no se promueven los suelos urbanizables, por la diferencia de costes anterior- 
mente analizada, y que en último término impide la creación de un núcleo estructurante que actúe como centro de servicios.

Por otra parte, es llamativo el incumplimiento por parte de las Diputaciones Forales de la obligación que les asignó la LSUPV, en vigor desde el año 2006, de elaborar los inventarios de NR existentes en sus respectivos Territorios Históricos (art. 29.7). El objeto de este Inventario se aclaró mediante el Decreto 105/2008 de Medidas Urgentes en desarrollo de la LSUPV, que en su artículo 7 establece que tal Inventario actúa como límite para la calificación de nuevos NR. En consecuencia y a falta de estos Inventarios, los Ayuntamientos podrán continuar generando nuevas calificaciones y delimitaciones de NR.

El desarrollo reglamentario de la LSUPV, a través del Decreto 105/2008 de Medidas Urgentes, no ha aclarado este panorama. Incluso se podría achacar nuevamente a la autoridad urbanística autonómica que continúa sin asignar un encaje a esta categoría dentro del esquema de clasificación del suelo, minusvalorando las repercusiones territoriales que ya está ocasionando desde la anterior Ley 5/98. En este sentido, el Decreto autoriza a que estos NR se conviertan en las verdaderas lanzaderas de la ocupación dispersa del territorio al permitir que sigan creciendo hasta completar las previsiones que les asigne el planeamiento y, que una vez colmatados, puedan clasificarse como suelo urbano o urbanizable . Es decir, en un futuro cercano podrían proliferar los municipios con varios focos de crecimiento urbano dispersos y de baja densidad.

Los Planes Territoriales Parciales empiezan a reflejar las dimensiones de las disfunciones que genera esta categoría urbanística. Según se recogía más arriba, algunos de ellos se pronuncian claramente en sentido crítico respecto a la proliferación de NR. Sin embargo, sigue faltando la determinación de poner fin a su desarrollo. Las propuestas para «congelar» futuras revisiones de planeamiento que aún no son más que sugerencias de los equipos redactores, pueden resultar ineficaces si se ejecutan los desarrollos previstos en los planes municipales actualmente aprobados, vistas las dimensiones que podría alcanzar el continuo urbanizado disperso.

Podría concluirse que la administración urbanística y de planificación territorial continúa sin apreciar las repercusiones que sobre la sostenibilidad del territorio está provocando la proliferación de esta categoría urbanística. La en-

\footnotetext{
${ }_{4}^{4}$ Art.5.1. «Los suelos no urbanizables de núcleo rural y que hubieran completado su desa rrollo conforme a las previsiones de la Ley 5/1998, podrán seguir siendo considerados al amparo de esta misma clasificación siempre que los mismos no sean objeto de nuevos desarrollos, en cuyo caso deberán ser objeto de reclasificación como suelo urbano o urbanizable según corresponda con la Ley 2/2006, de Suelo y Urbanismo, de acuerdo con el modelo de ordenación definido en el planeamiento territorial».
} 
tidad territorial del fenómeno es particularmente acusada en Bizkaia, según ponen de manifiesto los datos relativos al crecimiento del uso residencial en SNU que se han presentado más arriba, y que no deja indemne ni siquiera a su espacio protegido más emblemático: la Reserva de la Biosfera de Urdaibai (RBU).

La uRbanización de los Núcleos RuRALes en la Reserva de la Biosfera DE URDAIBAI

La dinámica de la urbanización difusa asociada a la figura del NR se materializa en la RBU incluso con mayor intensidad que en el resto del territorio. Sujeta a la misma legislación urbanística, con la única diferencia de que sus NR se hallan catalogados en el correspondiente Plan Rector de Uso y Gestión (PRUG), el valor ambiental añadido que le vale su título de Reserva, en un momento en que concurren otros factores como la mejora de las conexiones con Bilbao, la carestía de la vivienda en el área metropolitana y la salida de empleo industrial al corredor Txorierri-Ibaizabal, próximo a Urdaibai, explican la fuerza del proceso. Los saldos migratorios positivos para el conjunto de la RBU han propiciado el paso de cierto porcentaje de segundas a primeras residencias en la zona costera, pero también un incremento notable en el número de viviendas de carácter unifamiliar, en buena medida, ligadas a los NR a día de hoy reconocidos por el PRUG en vigor.

\section{Los Núcleos Rurales de Urdaibai}

El Plan Rector de Uso y Gestión (PRUG) aprobado en el año 1993 para la RBU ya se refería al Núcleo Rural o de Población como aquellas áreas de edificaciones agrícolas y residenciales que conformaban un núcleo a la entrada en vigor de la Ley 5/89 de Protección y Ordenación de Urdaibai. El PRUG definió el NR como aquel «[...] suelo rústico con calificación global residencial, y que tiene por misión albergar los asentamientos agrícolas, residenciales y equipamientos necesarios para poder desarrollar la producción de recursos del medio natural en el territorio» (art. 95); sin embargo, a renglón seguido abría la puerta al uso residencial sin vínculo con el medio rural al señalar que «[...] el uso predominante del núcleo de población es el residencial — vivienda uni o bifamiliar- ligado o no a explotación agrícola ganadera» (art. 96). Por lo demás, se especificaba que el número máximo de viviendas a albergar en edifica- 
ciones de nueva planta nunca podría superar al de las existentes a la entrada en vigor del propio PRUG. Como puede observarse, el carácter y posibilidades edificatorias otorgados por el Plan Rector a los NR de Urdaibai parecen precursores de la categoría del SNU que más tarde instituyó la Ley 5/98 para el conjunto del territorio vasco, a cuya definición estricta se adaptará el propio PRUG de Urdaibai en su Modificación de 2003.

FIGURA 2

NÚCLEOS RURALES DE LA RBU (PRUG 2003)

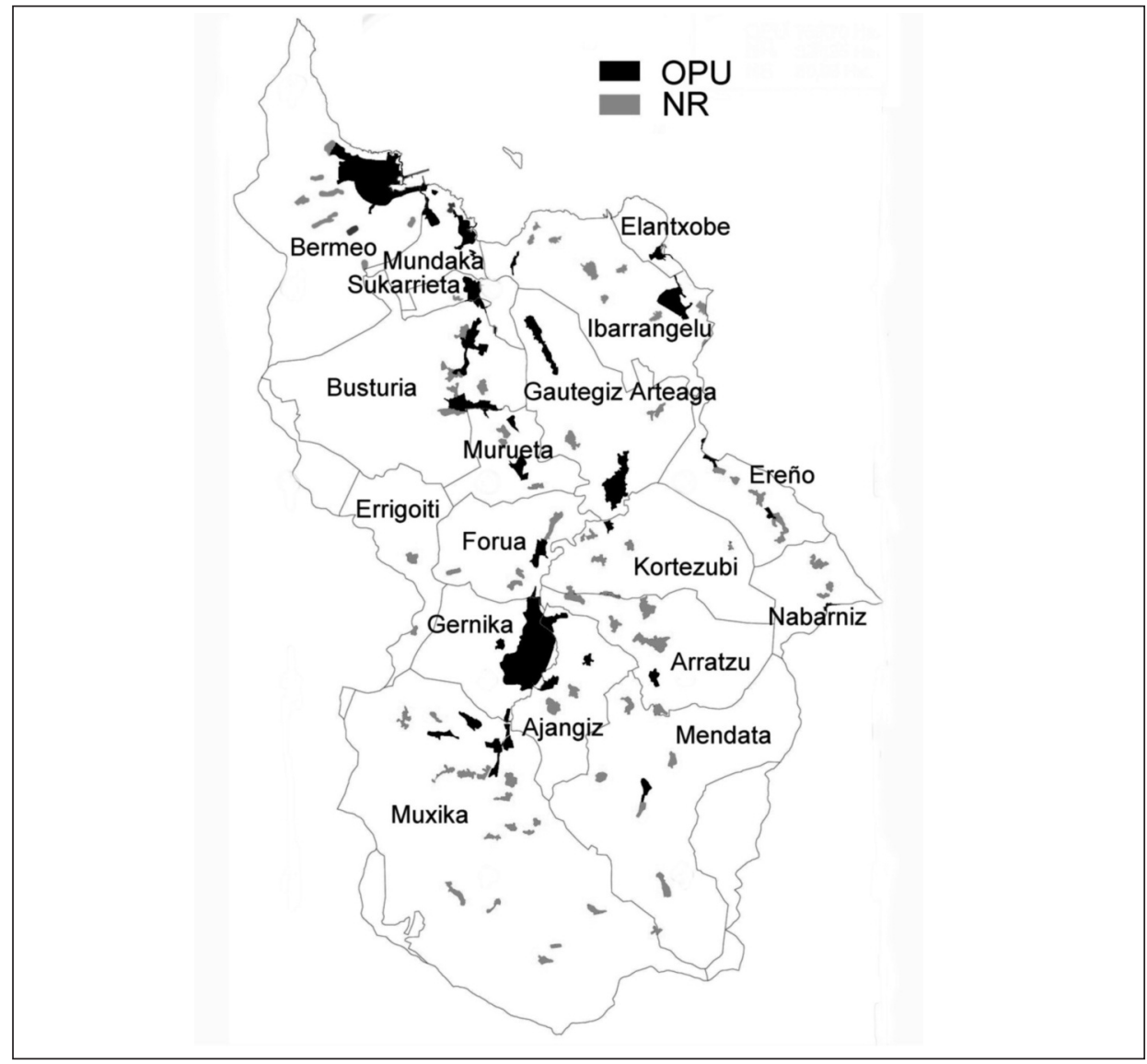

Fuente: Modificación PRUG Urdaibai, 2003.

Estudios Geográficos, Vol. LXXII, 271, pp. 371-401, julio-diciembre 2011 ISSN: 0014-1496, eISSN: 1988-8546, doi: 10.3989/estgeogr.201126 
En 1993 el PRUG delimitó 74 NR en Urdaibai, que en conjunto ocupaban una superficie de 328,70 ha, frente a las 669,86 ha que entonces cubrían los núcleos urbanos. La modificación en 2003 del PRUG supuso respecto a los NR su ampliación hasta un total de 77 , incrementándose la superficie que ocupan a 387,25 ha por 759,70 ha urbanas y urbanizables. Los nuevos NR fueron asumidos por el PRUG a iniciativa de los gobiernos municipales, que previamente los habían incluido en sus Normas Subsidiarias (NNSS) al amparo de la Ley 5/98. Cierta falta de concreción en la Ley así como la voluntad de los municipios de contentar el interés de sus vecinos condujo a la aparición de nuevos NR donde antes no los hubo. Además las NNSS del municipio de Mendata recogen dos NR no catalogados en el PRUG, Olabe y Zoloaurren.

Barrenetxea puso de relieve algunos aspectos de la Ley 5/98 que no quedaban suficientemente expresos; así sucede con la definición de «caserío», que no se sabe si hace alusión al edificio en sí mismo o al número de viviendas que contiene, siendo relativamente habituales los caseríos que albergan dos viviendas independientes. Otro tanto ocurre con el concepto de «espacio público» en torno al que esos seis o más caseríos deben organizarse para constituir un NR. En estas circunstancias, «Lo que se hace en la práctica es encontrar nuevos "espacios públicos" sobre los cuales justificar la existencia de otros núcleos rurales» (Barrenetxea Apraiz, 2000, p. 20), pasándose también por alto la limitación de no poder generar el doble de las edificaciones existentes — según sucede en el NR de Anzoras Sur en Ibarrangelu - o sobrepasando el número máximo de 30 viviendas - NR de Zilloniz o Astelarra en Muxika, Gabika en Ereño, Akorda y Arboliz en Ibarrangelu,... - . Por último, cuando el número de caseríos de un núcleo rural está próximo al máximo de viviendas permitidas la opción es segregarlo en varios NR, de forma que al menos pueda duplicarse el número de viviendas — caso de Besangiz en Muxika.

Muchos Ayuntamientos de la RBU han convertido los NR en su actuación urbanística preferente y no dudan a la hora de superar los escollos que la Ley plantea. A las ventajas económicas que la demanda de vivienda unifamiliar en el ámbito rural encuentra en esta calificación, se suma la propia presión de los vecinos, como se intuye en la modificación de las NNSS de Muxika en 2001, cuando se señala que en la medida de los posible se tratará de asignar «[...] a los caseríos de cada zona la viabilidad de construcción de al menos una nueva vivienda en alguna parcela de su propiedad» (Bilbao Uribarri, 2007, p. 90). Respecto a éste y otros muchos comportamientos similares de las corporaciones municipales, debe pensarse que los precios que llegan a pagarse por una parcela con derecho a edificación de vivienda unifamiliar son astronómicos, así como que la mayor parte de estos pueblos son pequeños, las relaciones es- 
trechas, una parte importante de la población es propietaria de caseríos con terrenos... Condiciones todas que llevan a que los gobiernos municipales adopten la política del «café para todos».

\section{CUADro 2}

\section{SUPERFICIE Y NÚMERO DE VIVIENDAS DE LAS CLASES} DE SUELO RESIDENCIAL

\begin{tabular}{|c|c|c|c|c|c|c|c|c|c|c|c|}
\hline & \multicolumn{6}{|c|}{ Superficie de clases de suelo residencial } & \multicolumn{3}{|c|}{$\begin{array}{c}\mathrm{N}^{0} \text { de viviendas } \\
\text { por clase de suelo }\end{array}$} & \multicolumn{2}{|c|}{$\begin{array}{l}\text { Suelo }\left(\mathrm{m}^{2}\right) / \\
\text { vivienda }\end{array}$} \\
\hline & \multicolumn{2}{|c|}{$\begin{array}{c}\text { Urbano } \\
\text { residencial } \\
(\mathrm{SUr})\end{array}$} & \multicolumn{2}{|c|}{$\begin{array}{c}\text { Urbanizable } \\
\text { residencial (SU) }\end{array}$} & \multicolumn{2}{|c|}{$\begin{array}{c}\text { No Urbanizable } \\
\text { residencial (SNU) }\end{array}$} & \multirow[t]{2}{*}{ SUr } & \multirow[t]{2}{*}{ SU } & \multirow[t]{2}{*}{ SNU } & \multirow[t]{2}{*}{ SUr } & \multirow[t]{2}{*}{ SNU } \\
\hline & Has. & $\%$ & Has. & $\%$ & Has. & $\%$ & & & & & \\
\hline Ajangiz & 5,05 & 26,9 & 0 & 0,0 & 13,75 & 73,1 & 47 & 0 & 30 & $1.074,5$ & $4.583,3$ \\
\hline Arratzu & 6,74 & 14,8 & 0 & 0,0 & 38,8 & 85,2 & 28 & 0 & 65 & $2.407,1$ & $5.969,2$ \\
\hline Bermeo & 63,58 & 86,0 & 10,37 & 14,0 & 0 & 0,0 & 7.842 & 40 & 550 & 81,1 & 0,0 \\
\hline Busturia & 44,1 & 53,5 & 9,02 & 10,9 & 29,32 & 35,6 & 929 & 2 & 353 & 474,7 & 830,6 \\
\hline Elantxobe & 4,16 & 78,6 & 1,13 & 21,4 & 0 & 0,0 & 396 & 1 & 17 & 105,1 & 0,0 \\
\hline Ereño & 6,19 & 18,2 & 4,29 & 12,6 & 23,56 & 69,2 & 83 & 0 & 99 & 745,8 & $2.379,8$ \\
\hline Errigoiti & 12,91 & 64,3 & 0 & 0,0 & 7,17 & 35,7 & 82 & 0 & 178 & $1.574,4$ & 402,8 \\
\hline Forua & 8,27 & 35,9 & 0 & 0,0 & 14,74 & 64,1 & 216 & 0 & 244 & 382,9 & 604,1 \\
\hline $\begin{array}{l}\text { Gautegiz } \\
\text { Arteaga }\end{array}$ & 73,28 & 86,2 & 0 & 0,0 & 11,78 & 13,8 & 408 & 0 & 30 & $1.796,1$ & $3.926,7$ \\
\hline Gernika-L. & 97,28 & 77,5 & 28,21 & 22,5 & 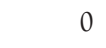 & 0,0 & 6.798 & 463 & 0 & 143,1 & - \\
\hline Ibarrangelu & 24,45 & 48,0 & 0 & 0,0 & 26,54 & 52,0 & 457 & 0 & 68 & 535,0 & $3.902,9$ \\
\hline Kortezubi & 3,87 & 13,1 & 0 & 0,0 & 25,68 & 86,9 & 40 & 0 & 134 & 967,5 & $1.916,4$ \\
\hline Mendata & 8,16 & 16,0 & 0 & 0,0 & 42,93 & 84,0 & 105 & 0 & 210 & 777,1 & $2.044,3$ \\
\hline Mundaka & 26,66 & 85,9 & 0 & 0,0 & 4,38 & 14,1 & 1.422 & 0 & 112 & 187,5 & 391,1 \\
\hline Murueta & 17,27 & 55,9 & 1,82 & 5,9 & 11,83 & 38,3 & 62 & 0 & 44 & $2.785,5$ & $2.688,6$ \\
\hline Muxika & 10,03 & 13,2 & 9,27 & 12,2 & 56,44 & 74,5 & 89 & 43 & 560 & $1.127,0$ & $1.007,9$ \\
\hline Nabarniz & 6,93 & 21,8 & 0 & 0,0 & 24,83 & 78,2 & 58 & 0 & 92 & $1.194,8$ & $2.698,9$ \\
\hline Sukarrieta & 16,53 & 72,5 & 3,6 & 15,8 & 2,66 & 11,7 & 306 & 7 & 57 & 540,2 & 466,7 \\
\hline $\mathrm{RBU}$ & 435,46 & 52,0 & 67,71 & 8,1 & 334,41 & 39,9 & 19.368 & 556 & 2843 & 224,8 & $1.176,3$ \\
\hline
\end{tabular}

Fuente: Udalplan 2008. 
Las consideraciones anteriores tienen un claro reflejo en los datos; como puede observarse en el cuadro 2, se da la particularidad de que muchos municipios de la RBU cuentan con una superficie de uso residencial en SNU que supera ampliamente la localizada en suelo urbano y urbanizable. De hecho, la escasa representación del suelo urbanizable en el conjunto de la RBU debe relacionarse con el extraordinario desarrollo de la figura del NR. Sólo Gernika y Bermeo presentan la tendencia clara a la formación de un núcleo urbano consolidado. En el extremo opuesto, Muxika, el municipio de mayor extensión territorial de toda la cuenca de Urdaibai, se decanta claramente por un patrón difuso basado en un elevado número de NR. De la misma forma muchos pequeños municipios de la margen derecha de la Ría de Urdaibai, como Ajangiz, Arratzu, Kortezubi... apuestan por la figura del NR en SNU, frente al desarrollo de los suelos urbanos y urbanizables. Cabe preguntarse por la sostenibilidad que subyace bajo esta apuesta si se repara en los ratios de suelo residencial por vivienda que se alcanzan en el Suelo No Urbanizable, frente al Urbanizable.

En definitiva, la escala local no parece ser la adecuada para gestionar el NR ni siquiera en la RBU, donde la existencia de un documento de ordenación y unos órganos de gestión superiores no sólo no han garantizado el uso «razonable» de la figura NR, sino que tampoco han sido capaces de impedir las triquiñuelas para forzar la Ley a favor de su máximo desarrollo.

\section{El desarrollo urbanístico en los Núcleos Rurales de Urdaibai}

En términos generales, la población que alberga la RBU se ha mantenido prácticamente estable durante las dos últimas décadas, pasando de 44.090 habitantes en 1991 a 43.863 en 2006. Sin embargo, un análisis más detallado deja entrever que la tendencia descendente se mantuvo hasta 2001, mientras en el quinquenio 2001-2006 se aprecia un incremento poblacional que en términos porcentuales se acerca al 2\%. A escala municipal las situaciones son bastante contrastadas; en tanto que Elantxobe, Nabarniz, Muxika, Ereño o Bermeo han sufrido pérdidas de población, otros como Murueta, Sukarrieta, Ajangiz o Arteaga registran importantes crecimientos.

El análisis geográfico indica que los crecimientos positivos de mayor intensidad se concentran en los municipios situados en el eje de la Ría de Urdaibai, mientras que los más excéntricos, ubicados en los márgenes montañosos, así como algunos de los costeros, prácticamente colmatados desde el punto de vista urbanístico, han registrado las pérdidas de población más acusadas. Se 
FIGURA 3.

CRECIMIENTO PORCENTUAL DE LA POBLACIÓN 1991-2006

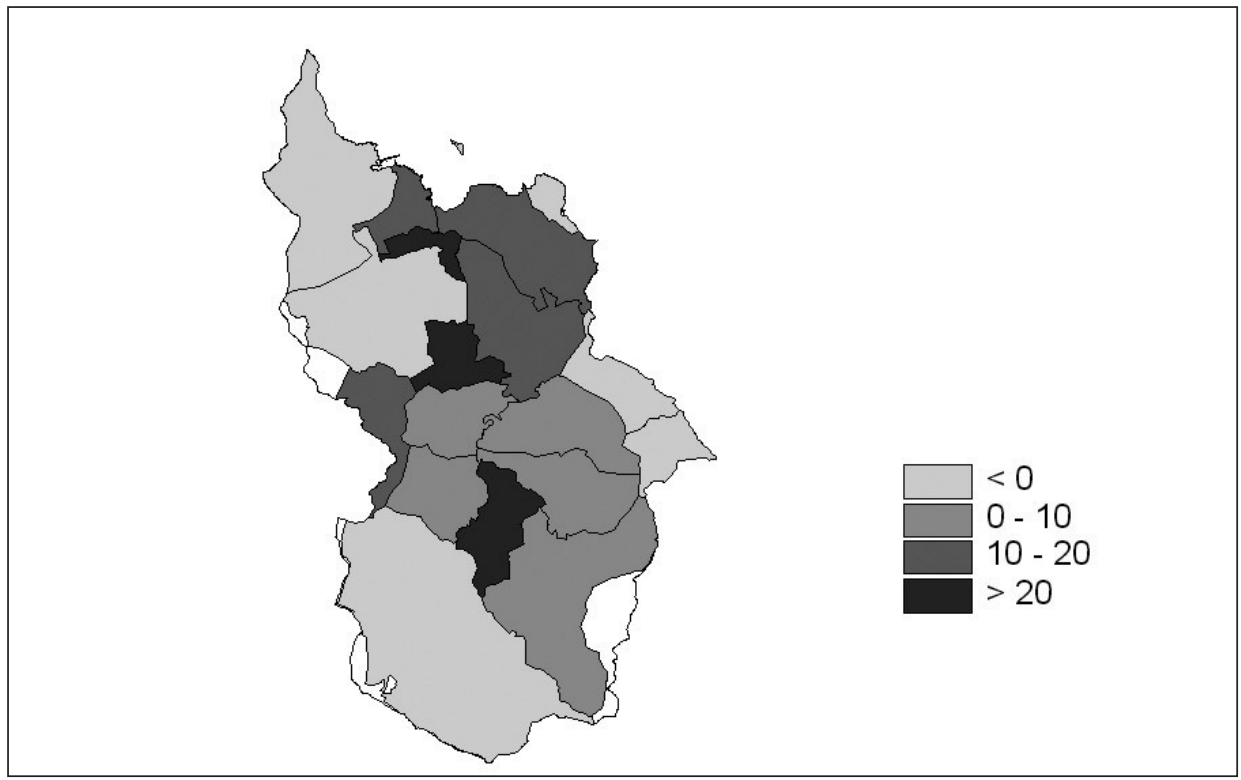

Fuente: EUSTAT. Elaboración propia.

podría deducir, por lo tanto, un mayor dinamismo para aquellas zonas que suman a sus valores ambientales y paisajísticos, una baja densidad demográfica y una buena accesibilidad.

La causa del incremento de población que han conocido estos municipios hay que buscarla en las migraciones internas, puesto que todos los que conforman la RBU registran para el periodo 1991-2006 saldos naturales de carácter negativo, debidos al envejecimiento de la población que propició el éxodo rural en la comarca hasta bien avanzado el siglo xx. No obstante, en el quinquenio 2001-2006 municipios como Mendata, Sukarrieta o Ajangiz han revertido el saldo vegetativo como consecuencia de cierto rejuvenecimiento de su población, debido precisamente a las tasas migratorias positivas. En general, los municipios con crecimientos positivos se corresponden con los que tienen los saldos migratorios favorables más elevados, mientras que los que han perdido población muestran valores más moderados o incluso negativos. 
CuAdro 3

TASAS DE CRECIMIENTO VEGETATIVO Y MIGRACIÓN NETA ANUAL (\%), 1991-2006

\begin{tabular}{lcccc}
\hline & Tasa de crecimiento vegetativo & \multicolumn{2}{c}{ Tasa de migración neta } \\
\hline Ajangiz & $1991-2006$ & $2001-2006$ & $1991-2006$ & $2001-2006$ \\
Arratzu & $-1,4$ & 0,4 & 12,9 & 5,8 \\
Bermeo & $-7,8$ & $-8,9$ & $-0,5$ & $-8,7$ \\
Busturia & $-3,3$ & $-2,3$ & 0,5 & 6,1 \\
Elantxobe & $-9,5$ & $-8,7$ & 5,4 & 10,0 \\
Ereño & $-11,8$ & $-9,0$ & $-0,4$ & 8,1 \\
Errigoiti & $-5,4$ & $-3,9$ & 1,9 & 14,4 \\
Forua & $-9,6$ & $-7,4$ & 11,2 & 9,6 \\
Gautegiz-A. & $-3,9$ & $-6,5$ & 3,0 & 0,8 \\
Gernika-L. & $-2,0$ & $-2,3$ & 13,6 & 11,0 \\
Ibarrangelu & $-0,9$ & $-0,3$ & 3,0 & 11,8 \\
Kortezubi & $-7,1$ & $-3,8$ & 9,1 & 9,6 \\
Mendata & $-4,1$ & $-1,7$ & 8,4 & 13,4 \\
Murueta & $-5,2$ & 1,4 & 8,3 & 8,4 \\
Muxika & $-7,8$ & $-9,0$ & 24,1 & 48,3 \\
Mundaka & $-1,0$ & 0,0 & $-1,6$ & 2,0 \\
Nabarniz & $-7,3$ & $-7,7$ & 7,4 & 2,5 \\
Sukarrieta & $-5,2$ & $-0,7$ & 0,8 & 4,5 \\
\hline RBU & $-2,2$ & 2,0 & 15,6 & 12,9 \\
\hline
\end{tabular}

Fuente: EUSTAT. Elaboración Propia.

No resulta fácil trasladar la evolución demográfica de los últimos años a los NR de Urdaibai, ya que los datos referidos a unidades de población inferiores al municipio prácticamente se limitan a los volúmenes absolutos que ofrece el Nomenclátor. De acuerdo con esta fuente, entre 1991 y 2006 los NR de la RBU registraron un incremento del 9,1\%, se pasa de 3.125 a 3.409 habitantes. No obstante, este dato que pudiera parecer muy significativo en relación al ligero descenso que presenta la población en el conjunto de la RBU para el mismo período debe ser matizado. Por una parte, no se dispone de datos para los municipios de Busturia, Ibarrangelu, Kortezubi, Mundaka y Sukarrieta y, además, en Forua y Arratzu varía la agrupación de los núcleos de población a lo largo del período; por otra parte y, más importante, los crecimientos positivos corresponden a los NR de tres únicos municipios: Murueta, Gautegiz-Arteaga y 
Errigoiti, alcanzando una dimensión muy relevante en el caso de los dos primeros. En el resto se registran pérdidas, las más intensas en Nabarniz, seguidas de Ajangiz, Mendata...

CUADRO 4

POBLACIÓN EN LOS NR DE URDAIBAI, 1991-2006

\begin{tabular}{|c|c|c|c|c|c|c|}
\hline \multirow[b]{2}{*}{ Municipio } & \multirow[b]{2}{*}{$\mathrm{N}^{\circ}$ de NR } & \multicolumn{4}{|c|}{$\begin{array}{c}\text { Población de los Núcleos Rurales } \\
\text { de la RBU }\end{array}$} & \multirow{2}{*}{$\begin{array}{c}\begin{array}{c}\text { Evolución } \\
\text { porcentual }\end{array} \\
1991-2006\end{array}$} \\
\hline & & 1991 & 1996 & 2001 & 2006 & \\
\hline Ajangiz & 2 & 235 & 179 & 192 & 203 & $-13,6$ \\
\hline Arratzu & 5 & - & 265 & 248 & 233 & $-12,1$ \\
\hline Bermeo $(* 3 *)$ & 8 & 404 & 372 & 370 & 352 & $-12,9$ \\
\hline Busturia $(* 2 *)$ & 5 & & & & & \\
\hline Elantxobe $(* 1 *)$ & 0 & - & - & - & - & \\
\hline Ereño $(* 4 *)$ & 4 & 277 & 268 & 253 & 257 & $-7,2$ \\
\hline Errigoiti & 2 & 102 & 112 & 119 & 117 & 14,7 \\
\hline Forua & 4 & - & 190 & 193 & 185 & $-2,6$ \\
\hline Gautegiz Arteaga & 2 & 89 & 107 & 127 & 111 & 24,7 \\
\hline Gernika-Lumo $\left({ }^{*} 1^{*}\right)$ & 0 & - & - & - & - & \\
\hline Ibarrangelu $(* 2 *)$ & 9 & & & & & \\
\hline Kortezubi $(* 2 *)$ & 6 & & & & & \\
\hline Mendata & 7 & 283 & 212 & 239 & 247 & $-12,7$ \\
\hline Mundaka $(* 2 *)$ & 2 & & & & & \\
\hline Murueta $(* 4 *)$ & 3 & 201 & 202 & 222 & 302 & 50,2 \\
\hline Muxika $(* 4 *)$ & 17 & 1.443 & 1.415 & 1.341 & 1.331 & $-7,8$ \\
\hline Nabarniz & 3 & 91 & 72 & 71 & 71 & $-22,0$ \\
\hline Sukarrieta $(* 2 *)$ & 1 & & & & & \\
\hline Total población en NR & 79 & 3.125 & 3.394 & 3.375 & 3.409 & 9,1 \\
\hline
\end{tabular}

Fuente: NNSS, INE y EUSTAT. Elaboración propia5.

$5\left({ }^{*} 1^{*}\right)$ Municipios que no tienen entidades clasificadas como Núcleo Rural. $\left({ }^{*}{ }^{*}\right)$ Municipios en los que la población de los NR no puede segregarse de la de los OPU. $(* 3 *)$ No se incluye el Núcleo Rural de Itxasalde, agrupado con Bermeo-OP. $\left({ }^{*} 4^{*}\right)$ Municipios en los que se ha asimilado a los NR la población de los OPU. 
No obstante, si el crecimiento demográfico afecta solamente a unos pocos NR de Urdaibai, el urbanístico, constatable a partir del mero recorrido de campo, es una realidad que sin ser generalizable a todos ellos afecta a una parte sustancialmente mayor de los mismos. Esta aparente paradoja se explica de un lado por el acusado envejecimiento de la población y consecuente mayor mortalidad en los NR; no debe olvidarse que se trata de barrios de caseríos cuya pérdida de funcionalidad económica supuso el abandono de muchos y la marginalización en cuanto que explotaciones agrarias de prácticamente todos ellos, y de otro porque una parte de la nueva vivienda construida se destina a

\section{CUADRO 5}

CAPACIDAD RESIDENCIAL Y GRADO DE EJECUCIÓN URBANÍSTICA EN LOS NR DE URDAIBAI, 2000-2008

\begin{tabular}{|c|c|c|c|c|c|c|c|c|}
\hline Municipio & $\begin{array}{l}\mathrm{N}^{o} \mathrm{de} \\
\mathrm{NR}\end{array}$ & $\begin{array}{c}\text { Vivienda } \\
\text { existente } \\
2000\end{array}$ & $\begin{array}{l}\text { Máximo } \\
\text { establecido }\end{array}$ & $\begin{array}{c}\text { Licencias } \\
\text { Cons- } \\
\text { trucción } \\
2000-08\end{array}$ & $\begin{array}{c}\text { Total } \\
\text { ejecutada } \\
\text { hasta } 2008\end{array}$ & $\begin{array}{l}\text { Vacantes } \\
\text { en } 2008\end{array}$ & $\begin{array}{l}\text { \% ejecutadas } \\
2000-08 \\
\text { sobre nuevas } \\
\text { concedidas }\end{array}$ & $\begin{array}{l}\text { \% ejecución } \\
\text { sobre la } \\
\text { dimensión } \\
\text { máxima }\end{array}$ \\
\hline Ajangiz & 2 & 28 & 51 & 4 & 32 & 19 & 17,4 & 62,7 \\
\hline Arratzu & 5 & 65 & 99 & 2 & 67 & 32 & 5,9 & 67,7 \\
\hline Bermeo & 8 & & & & & & & \\
\hline Busturia & 5 & 52 & 68 & 5 & 57 & 11 & 31,3 & 83,8 \\
\hline Ereño & 4 & 48 & 74 & 5 & 53 & 21 & 19,2 & 71,6 \\
\hline Errigoiti & 2 & 25 & 45 & 1 & 26 & 19 & 5,0 & 57,8 \\
\hline Forua & 4 & 44 & 72 & 9 & 53 & 19 & 32,1 & 73,6 \\
\hline Gautegiz-A. & 2 & & & & & & & \\
\hline Ibarrangelu & 9 & 94 & 180 & 8 & 102 & 78 & 9,3 & 56,7 \\
\hline Kortezubi & 6 & 57 & 95 & 6 & 63 & 32 & 15,8 & 66,3 \\
\hline Mendata & 7 & 96 & 161 & 3 & 99 & 62 & 4,6 & 61,5 \\
\hline Mundaka & 2 & 8 & 15 & 1 & 9 & 6 & 14,3 & 60,0 \\
\hline Murueta & 3 & 22 & 38 & 6 & 28 & 10 & 37,5 & 73,7 \\
\hline Muxika & 17 & 140 & 244 & 24 & 164 & 80 & 23,1 & 67,2 \\
\hline Nabarniz & 3 & 25 & 38 & 3 & 28 & 10 & 23,1 & 73,7 \\
\hline Sukarrieta & 1 & 4 & 6 & 0 & 4 & 2 & 0,0 & 66,7 \\
\hline$\overline{\mathrm{RBU}}$ & 79 & 708 & 1186 & 77 & 785 & 401 & 16,1 & 66,2 \\
\hline
\end{tabular}

Fuente: Normas Subsidiarias de Planeamiento y Patronato de la RBU. 
segunda residencia. Se explica así que el desarrollo urbanístico de los NR apenas tenga reflejo en su volumen demográfico.

La evolución en el número de viviendas de los NR tras la entrada en vigor de la Ley 5/98 puede seguirse a partir de las NNSS y las licencias de construcción concedidas por los municipios de la RBU. La mayor parte de las NNSS vigentes en los municipios de Urdaibai se aprobaron en el año 2000, una vez que se había producido su adaptación a la Ley 5/98 que obligaba a contabilizar las viviendas existentes en cada uno de sus NR en el momento de la redacción, así como a consignar el crecimiento residencial previsto. A esos datos pueden añadirse los relativos al número de licencias de edificación concedidas desde entonces, de manera que es posible cuantificar la intensidad del proceso de urbanización a partir del grado de ejecución de la capacidad residencial máxima prevista en cada uno de ellos.

A partir de los datos puede observarse en primer lugar que mientras en la situación de partida casi tres cuartas partes de los NR tenían una dimensión de entre 6 y 15 caseríos, en la situación de llegada prevista por las NNSS actualmente en vigor dominarán los núcleos de mayor tamaño, de los que una tercera parte superará las 21 viviendas - actualmente solo el 5\% alcanza esa envergadura-. Pero además y según muestra la figura 4, un 20\% de los NR de Urdaibai podrían sobrepasar el tope de 25 viviendas máximas previstas por la vigente Ley del Suelo para los NR; en otras palabras, 15 de los actuales NR podrían reclasificarse como suelo urbano.

Por otra parte, la prevención respecto a que el planeamiento no podrá originar un incremento del aprovechamiento urbanístico ni del número de viviendas superior a un $50 \%$ sobre el existente, puede interpretarse como referido al período de vigencia del plan, de manera que sucesivas modificaciones siempre posibilitarían llegar hasta el tope máximo sea cual sea el número de caseríos del que se parta (Bilbao Uribarri, 2007). De suceder así, una parte sustantiva de los NR de Urdaibai podrían convertirse en urbanizaciones de más de 25 viviendas, que clasificadas como suelo urbano podrían seguir desarrollándose en baja densidad —al ser la mayoría municipios menores de 3.000 habitantes, el estándar legal mínimo de densidad es de $0,25 \mathrm{~m}^{2}$ techo/ $\mathrm{m}^{2}$ suelo (art. 77.4 LSUPV)—. Todo ello llevaría al paradójico desarrollo polinuclear en baja densidad propio del urban sprawl en una Reserva de la Biosfera.

Respecto al desarrollo urbanístico registrado por los NR de Urdaibai tras la entrada en vigor de la Ley 5/98, puede seguirse a partir de las licencias de construcción concedidas. Entre 2000 y 2008 se han solicitado en Urdaibai en torno a 100 licencias de construcción de vivienda unifamiliar en SNU ligado a NR, de las que se han concedido y ejecutado 77 , quedando en esa fecha y de 
FIGURA 4

TAMAÑO PREVIO Y PREVISTO POR LAS NNSS EN VIGOR DE LOS NR EN LA RBU, SEGÚN NÚMERO DE VIVIENDAS

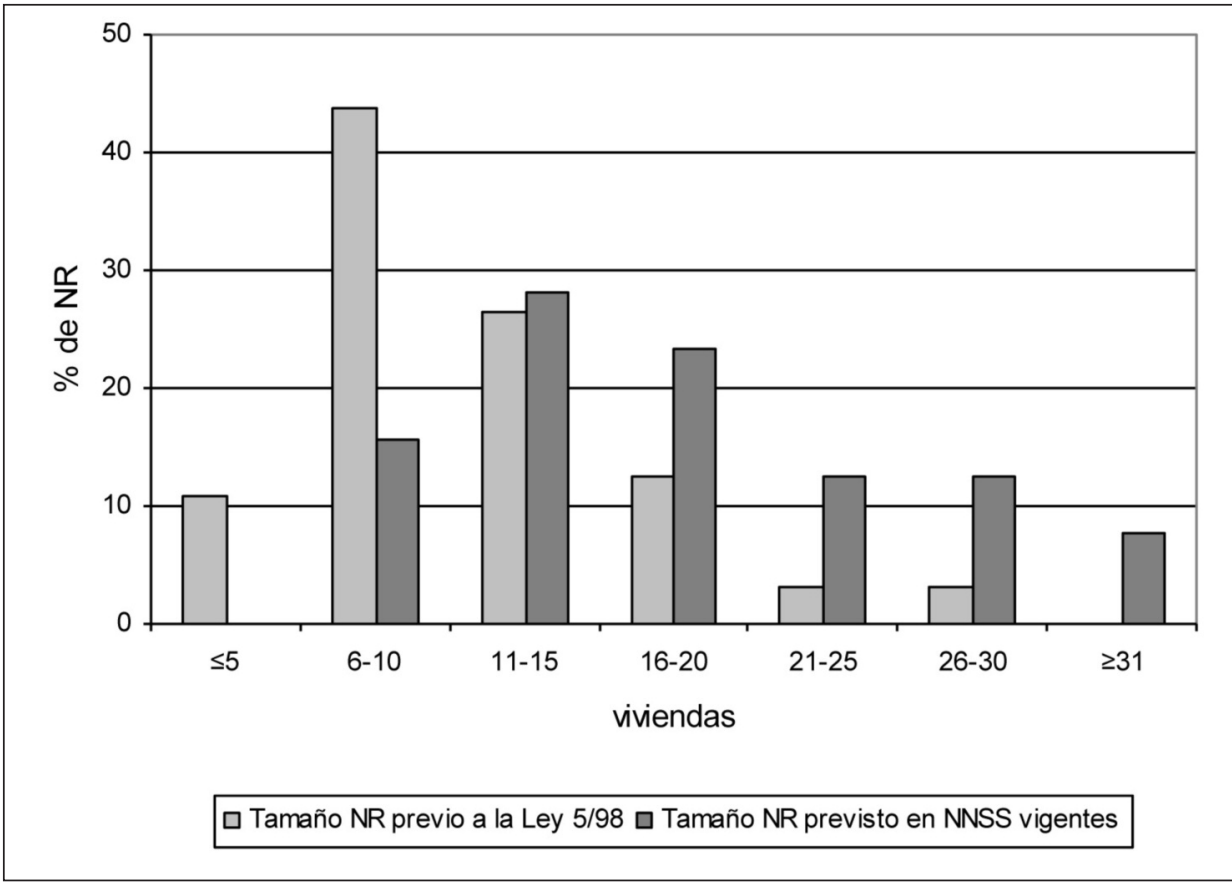

Fuente: Normas Subsidiarias y Patronato de la RBU. Elaboración propia.

acuerdo con el planeamiento vigente la posibilidad de construir 400 viviendas unifamiliares más en los NR de la Reserva. En otras palabras, en el período 2000-2008 se ha ejecutado aproximadamente un 16\% de la vivienda unifamiliar de nueva planta prevista en el SNU de Urdaibai.

Un dato que se hace más revelador si se profundiza algo más el análisis. Puede observarse que en casi la mitad de los NR de Urdaibai apenas se ha producido la construcción de nueva vivienda; por el contrario, un 20\% prácticamente ha colmatado la capacidad máxima de crecimiento que le otorgó el planeamiento. Las divergencias tienen que ver con dos parámetros: localización y recursos paisajísticos, de manera que los núcleos próximos a la BI-635 que vertebra de Norte a Sur la RBU, constituyéndose en un claro eje de centralidad, así como todos aquellos con vistas a la Ría de Urdaibai y al borde costero se constituyen en los NR realmente valorados. Estos últimos, a los que 
FIGURA 5

NIVEL DE EJECUCIÓN DE VIVIENDA SOBRE LA NUEVA VIVIENDA CONCEDIDA EN LOS NR CENTRALES Y EXCÉNTRICOS DE LA RBU, 2000-2008

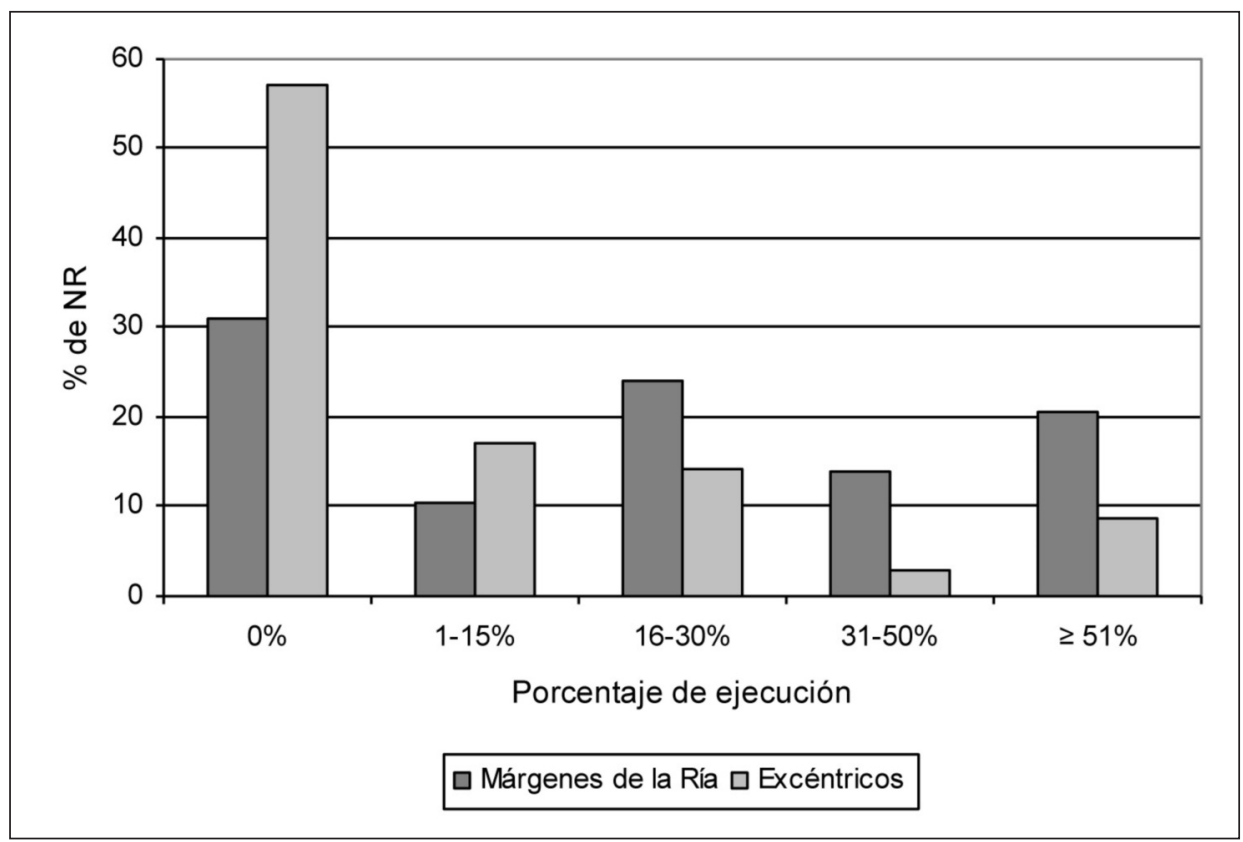

Fuente: Normas Subsidiarias y Patronato de la RBU. Elaboración propia.

aludiremos como NR centrales, representan el $40 \%$ sobre el total, frente a los NR excéntricos que ubicados en los márgenes montañosos resultan claramente marginales.

La figura 5 permite comprobar que si bien en más de la mitad de los NR excéntricos de la RBU no se ha construido nueva vivienda, ese porcentaje desciende hasta un tercio en los NR centrales, siendo que en una cuarta parte de estos últimos se ha construido, en apenas ocho años, más de la mitad de la nueva vivienda permitida por las correspondientes NNSS. A partir de este comportamiento diferenciado cabe extraer una conclusión importante que invalida el principal argumento esgrimido por las corporaciones municipales para justificar su apuesta por el desarrollo de los NR: la necesidad estratégica de fijar la población local; un planteamiento con el que la propia Comisión de Ordenación del Territorio del País Vasco se ha alineado en numerosas ocasiones. 
Se parte del derecho de los «hijos del caserío» a vivir en el lugar en que nacieron y la bondad territorial derivada del mantenimiento de la población asociada al hábitat disperso, en cuanto que dicha población gestiona y mantiene el territorio inmediato. No obstante, tanto si los propietarios de la vivienda de nueva construcción en los NR son autóctonos como si son foráneos, lo cierto es que, de acuerdo con los datos recabados mediante el trabajo de campo, en el 99\% de los casos ninguno de los dos grupos realiza ningún tipo de actividad agropecuaria que garantice el mantenimiento de la gestión territorial. Pero además de este hecho indiscutible, que en sí mismo debería resultar suficiente para cuestionar la oportunidad del crecimiento de los NR, los datos muestran con claridad que se desarrollan preferentemente los NR centrales, aquellos que presentan un interés claro como producto inmobiliario, en tanto que los NR excéntricos, donde realmente existen problemas de despoblación y envejecimiento, presentan ritmos de crecimiento bastante más modestos.

Los impactos ambientales y paisajísticos en los NR mejor valorados son evidentes, a su análisis se dedicará una próxima publicación, ahora sólo se trata de señalar que el proceso propicia la desnaturalización funcional del NR. Con toda facilidad las praderas pasan a convertirse en jardines de los chalets que ahora las ocupan; se asiste al tránsito de la Superficie Agraria Util - SAU- al Suelo Apto para Urbanizar -SAU-. En apenas ocho años se han construido en la RBU 80 viviendas unifamiliares que mínimamente ocupan unas 20 ha, si se tiene en cuenta la dimensión mínima que se exige a la parcela en SNU para poder acoger vivienda unifamiliar. Y si la magnitud de los datos no es notoriamente superior se debe a los altísimos precios que el estrecho mercado del suelo en un territorio secularmente convencido de que la tierra constituye el mejor patrimonio.

No obstante, incluso si en general los propietarios de caseríos tienden a evitar las ventas, los precios millonarios que una demanda de clase media-alta ofrece por una parcela hacen que en ciertos NR la capacidad residencial esté prácticamente colmatada y se solicite una revisión del planeamiento, para seguir creciendo. El caso del NR de Landa en el municipio de Murueta puede muy bien servir de ejemplo (figura 6); situado en la vega aluvial, el PRUG clasifica las tierras que lo circundan como «Área de Interés Agrario», si bien el interés que prospera es el inmobiliario.

A la ocupación y fragmentación de suelo agrario con carácter irreversible, se añade el hecho de que la especulación se implementa al conjunto de las tierras que, de acuerdo con el modelo de organización de los barrios de caseríos, rodea el NR propiamente dicho, dando como resultado una amortización del suelo rústico en cuanto que recurso agrario; un hecho que acelera el aban- 
FIGURA 6

DESARROLLO URBANÍSTICO DEL NR DE LANDA (MURUETA) EN LA RBU, 2000-2008

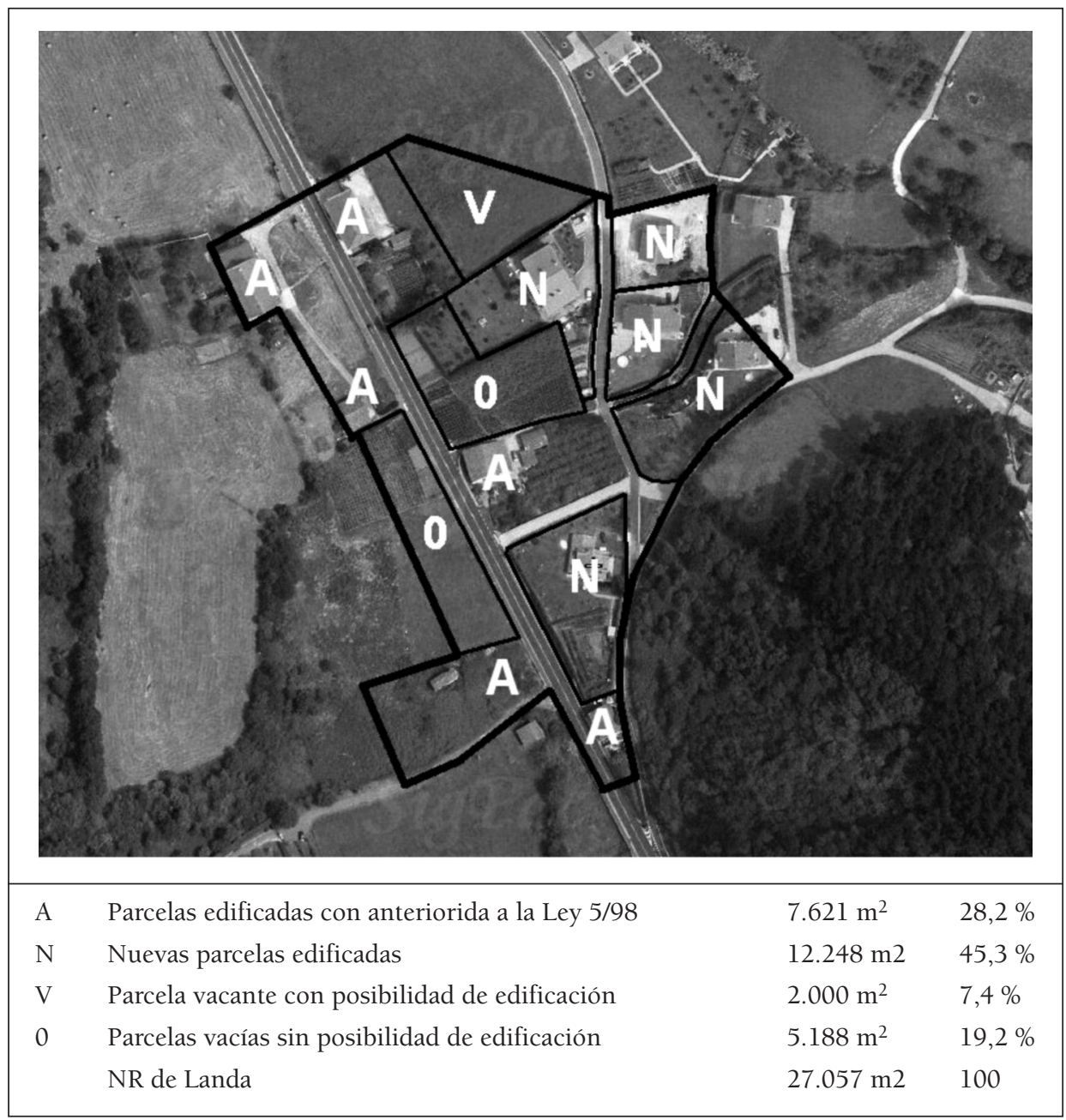

Fuente: Modificación de las NNSS de Murueta, 2004.

dono de la explotación agraria en los núcleos más afectados por el desarrollo urbanístico. Las secuelas paisajísticas del abandono se suman a las generadas por la propia implantación de nueva vivienda, que las más de las veces se produce sin unos mínimos de integración visual. En definitiva, comienzan a ma- 
terializarse el conjunto de los efectos no deseados propios del urban sprawl, con la particularidad de que lo hacen en un ámbito especialmente frágil y vulnerable sobre el que se incrementa la necesidad de nuevas infraestructuras y vías de comunicación, que contribuirán a generalizar la presión al conjunto de la RBU y realimentar el fenómeno.

\section{CONCLUSIONES}

La figura 2, donde se cartografían los NR de la RBU, muestra con toda elocuencia que es todo el conjunto territorial de Urdaibai el que se encuentra sometido al riesgo del urban sprawl, con independencia de que por el momento afecte en mayor medida a los NR con mejores niveles de centralidad o calidad paisajística. Esta realidad parece especialmente grave en un espacio protegido, en una Reserva de la Biosfera; no obstante, aún resulta más preocupante que el fenómeno no sea privativo de ésta, sino que afecte a todo el territorio vasco, particularmente en su vertiente atlántica. Se comprende mal que una Administración consciente de los costos socioambientales que genera el proceso de la urbanización difusa (Instituto de Estudios Territoriales de Bizkaia, 2003), haya promovido la figura urbanística que la propicia en el SNU.

La del Núcleo Rural en SNU es una figura urbanística incoherente con los principios de urbanismo sostenible. Nacido de una discutible práctica urbanística municipal, el NR fue legalizado sin un análisis territorial riguroso mediante la Ley 5/1998; la Ley 2/2006 de Suelo y Urbanismo del País Vasco lo consolida, delegando además en los Ayuntamientos su definición como Suelo No Urbanizable o Suelo Urbano, una vez alcanzada la cota de las 25 viviendas.

El atractivo que ofrece el Núcleo Rural desde el punto de vista de su calidad ambiental y paisajística, unido a sus ventajas como producto inmobiliario en cuanto que el propietario de la parcela queda exento de compartir plusvalías o asumir unos costes de urbanización, que finalmente se acometerán con financiación pública, explica la proliferación de esta figura contraria al interés municipal. La apuesta por el Núcleo Rural frente al suelo urbano, propia de la mayoría de los municipios de Urdaibai, es generalizable al conjunto de los municipios pequeños de la vertiente vasco-atlántica, donde la función pública urbanística queda fácilmente sometida a las pretensiones de los ciudadanos locales a partir de las relaciones de vecindad y parentesco con los miembros de la Corporación (TRLS, 2008).

Y si la escala local se ve desbordada por este conjunto de intereses, a la escala regional el proceso se le ha escapado de las manos al consolidar la figura 
del NR sin considerar suficientemente cual era la estructura del poblamiento y la magnitud que podía adquirir al basarlo en los crecimientos de cientos de barrios de caseríos; la falta de un análisis de costes y repercusiones de esta figura urbanística llevó a minusvalorar su riesgo potencial. Ni siquiera en una Reserva de la Biosfera, existiendo un PRUG que vincula y prevalece sobre el planeamiento urbanístico (art. 15 de la Ley 5/89 de Urdaibai), ha sido posible controlar el avance progresivo de esta calificación. La cuestión es que esos pequeños y espléndidos barrios de caseríos que acogen el urban sprawl siendo muchos no son infinitos, de manera que es obligado tratar con muchísimo tiento el fenómeno porque las posibilidades de ensayo están limitadas. ¿Será capaz la recién iniciada $2^{a}$ revisión del PRUG de Urdaibai de introducir una norma expresa que acabe con la posibilidad de clasificar nuevos Núcleos Rurales y limite el desarrollo de los ya catalogados?

Recibido: 30/05/2011

Aceptado: 10/11/2011

\section{BiBLiografía}

Agencia Europea de Medio Ambiente (AEMA) (2006): "Urban sprawl in Europe: The Ignored Challenge". Copenhague, 10. Disponible en http://www.eea.europa.eu/pu blications/eea_report_2006_10/eea_report_10_2006.pdf (consultado el 16 de noviembre de 2011).

Ainz Ibarrondo, M. J. (1999): "La proyección espacial del caserío vasco; desde su antigua condición de unidad agraria plurifuncional a la más nueva de suelo urbanizable". BAGE, 27, pp. 47-66.

Ainz Ibarrondo, M. J. (2001): El caserío vasco en el país de las industrias. Madrid, MAPA, Serie Estudios.

Ainz Ibarrondo, M. J. (2003): "El caserío ante la amenaza de la urbanización del campo", en Libro blanco de la Agricultura y el desarrollo rural. Madrid, MAPA.

Antolín Iria, J. E. (1999): El proceso de urbanización del suelo rural: la vivienda familiar sobre el suelo no urbanizable en Bizkaia (1981-1992). Lejona, Servicio Editorial de la Universidad del País Vasco.

Antrop, M. (2000): "Changing patterns in the urbanized countryside of western Europe". Landscape Ecology, 15/3, pp. 257-270.

Arroyo, M. (2001): "La Contraurbanización: un debate metodológico y conceptual sobre la dinámica de las Áreas Metropolitanas". Scripta Nova, 97. Disponible en http://www.ub.es/geocrit/sn-97.htm (consultado el 16 de noviembre de 2011). 
Barrenetxea Apraiz, J. C. (2000): Situación actual y regulación jurídica de los Núcleos Rurales en la Reserva de la Biosfera de Urdaibai. Patronato de Urdaibai. (No publicado).

Bilbao Uribarri, A. (2007): "Los núcleos rurales en el País Vasco como precursores de la dispersión urbana: la reserva de la biosfera de Urdaibai". Ciudad y Territorio Estudios Territoriales, 151, pp. 83-101.

Boyle, P. y Halfacree, K.: Migration into Rural Areas. Theories and Issues. Chichester, Wiley.

Camarero, L. A. (1993): Del éxodo rural y del éxodo urbano. Ocaso y renacimiento de los asentamientos rurales en España. Madrid, MAPA.

Congreso Mundial Vasco (1988): Urbanización del campo en los países industrializados. Barcelona, Oikos-Tau.

Diputación Foral de Bizkaia (2002): Plan Territorial Parcial del Área Funcional de Gernika-Markina. Bizkaia, Departamento de Transportes y Urbanismo. Disponible en http://www.bizkaia.net/hirigintza/LurraldekoZatiEgitasmoa/gernika/Avance/TOMO \%20I\%20Avance\%20Gernika.pdf (consultado el 16 de noviembre de 2011).

Diputación Foral de Bizkaia (2008): Plan Territorial Parcial del Área Funcional de Mungia. Bizkaia, Departamento de Transportes y Urbanismo. Disponible en http://www.bizkaia.net/hirigintza/lurraldekozatiegitasmoa/areas.asp? idarea $=4 \& T e$ m_Codigo=3727 (consultado el 16 de noviembre de 2011).

Diputación Foral de Bizkaia (2009): Plan Territorial Parcial del Área Funcional de Durango. Bizkaia, Departamento de Transportes y Urbanismo, 2009. Disponible en http://www.bizkaia.net/hirigintza/lurraldekozatiegitasmoa/durango/aprobacion_pr ovisional/Documentacion_escrita/castellano/CA_APROV_DURANGO_V5_INDICE\%20GENERAL\%20DEL\%20DOCUMENTO.pdf (consultado el 16 de noviembre de 2011).

Etxezarreta Zubizarreta, M. (1977): El caserío vasco. Bilbao, Fundación C. de Iturriaga y M. de Dañobeitia.

Fernández García, A. (2003): "Las pautas del crecimiento urbano postindustrial: de la rururbanización a la ciudad difusa”. Ería: Revista cuatrimestral de geografía, 60, pp. 88-92.

García de Cortázar J.A. et al. (1985): Bizcaya en la Edad Media. San Sebastián, Haramburu Editor.

García Fernández, J. (1975): Organización del espacio y economía rural en la España atlántica. Madrid, Siglo XXI.

García-Bellido, J. (2002): "La cuestión rural: patología urbanística del espacio rústico". Ciudad y Territorio. Estudio Territoriales, 132, pp. 277-321.

Gobierno Vasco (1997): Directrices de Ordenación Territorial de la Comunidad Autónoma del País Vasco (DOT). Departamento de Medio Ambiente, Planificación Territorial, Agricultura y Pesca. Disponible en http://www.ingurumena.ejgv.eu skadi.net/r49-565/es/contenidos/informacion/dots/es_1165/indice_c.html (consultado el 16 de noviembre de 2011). 
Gobierno Vasco (2003): Plan Rector de Uso y Gestión de la Reserva de la Biosfera de Urdaibai. Texto Refundido 2003. Departamento de Medio Ambiente, Planificación Territorial, Agricultura y Pesca. Disponible en http://www.ingurumena.ejgv. euskadi.net/r49-12872/es/contenidos/planes/prug/es_15318/adjuntos/prug.pdf (consultado el 16 de noviembre de 2011).

Instituto de Estudios Territoriales de Bizkaia (2003): Análisis socioeconómico de la evolución del Urban Sprawl en el Territorio Histórico de Bizkaia. Bilbao, Diputación Foral de Bizkaia.

Monclus, F. J, (ed.) (1998): La ciudad dispersa: suburbanización y nuevas periferias. Barcelona, Centre de Cultura Contemporània.

Observatorio de la Sostenibilidad en España (OSE) (2006): "Cambios de ocupación del suelo en España, 2006. País Vasco", pp. 402-413. Disponible en http://www.sostenibilidad-es.org/NR/rdonlyres/6B6B0D68-76E9-4456-B22ED8DFB0E85E72/131/0716PAISVASCO.pdf (consultado el 16 de noviembre de 2011).

Torres Elizburu, R. (2007): "Las migraciones internas en el País Vasco durante el periodo 1991-2001. Evidencias de un proceso de contraurbanización". BAGE, 43, pp. 85-105.

\section{RESUMEN}

En este artículo se analiza el proceso de urbanización que está registrando el Suelo No Urbanizable en el País Vasco. Apoyado territorialmente en el tradicional hábitat rural disperso y amparado jurídicamente por la figura urbanística Núcleo Rural que contempla la Legislación vasca, el urban sprawl amenaza al conjunto del territorio vasco, incluyendo sus espacios protegidos. El análisis se centra en el desarrollo del fenómeno en la Reserva de la Biosfera de Urdaibai, transcurrido un decenio desde la incorporación del Núcleo Rural al planeamiento urbanístico.

Palabras clave: País Vasco; Reserva de la Biosfera de Urdaibai; urban sprawl; Suelo No Urbanizable; Núcleo rural.

\section{AbSTRACT}

This article analyzes the process of urbanization that is registering the not-urban area in the Basque Country. Supported in the traditional dispersed rural habitat and legally protected by the "Rural Nucleus" urban figure referred to in the Basque Legislation, the urban sprawl is threatening the Basque territory, including protected areas. The analysis focuses on the progress of this phenomenon in the Urdaibai Biosphere Reserve, after a decade since the incorporation of the "Rural Nucleus" to the urban planning.

KeY wORDS: Basque Country; Urdaibai Biosphere Reserve; urban sprawl; non-urban area; Rural Nucleus. 


\section{RÉSUMÉ}

Cet article analyse le processus d'urbanisation qui se déroule sur les terres classées comme "terrain non constructible" dans le Pays Basque. Territorialement tenue à la traditionnelle habitat rural et protégée par la figure urbanistique "Núcleo Rural", etabliée par la loi basque, l'urban sprawl menace tout le Pays Basque, y compris ses aires protégées. Lanalyse se concentre sur le développement du phénomène dans la Réserve de Biosphère d'Urdaibai, après une décennie depuis l'introduction de la figure "Núcleo Rural" à la planification urbaine.

Mots ClÉs: Pays Basque; Réserve de la Biosphère d'Urdaibai; urban sprawl; Terrain non constructible; Núcleo rural. 